\title{
Cities for global health
}

\author{
(C) (1) OPEN ACCESS
}

In the first of a new series of articles on the role of cities in health, Majid Ezzati and colleagues call for greater action to reduce health inequalities within cities

\author{
Majid Ezzati professor of global environmental health ${ }^{1}$, Christopher $\mathrm{J}$ Webster dean and chair \\ professor of urban planning and development economics ${ }^{2}$, Yvonne G Doyle director for London ${ }^{3}$, \\ Sabina Rashid dean and professor ${ }^{4}$, George Owusu professor and director ${ }^{5}$, Gabriel M Leung dean \\ and chair professor of public health medicine ${ }^{6}$
}

\begin{abstract}
'School of Public Health, MRC-PHE Centre for Environment and Health, WHO Collaborating Centre on Non-Communicable Disease Surveillance and Epidemiology, Imperial College London,; ${ }^{2}$ Faculty of Architecture, The University of Hong Kong, Hong Kong, China; ${ }^{3}$ Public Health England, London, UK; ${ }^{4}$ James P Grant School of Public Health, BRAC University, Dhaka, Bangladesh; ${ }^{5}$ Centre for Urban Management Studies, Institute of Statistical, Social and Economic Research (ISSER), University of Ghana, Accra, Ghana; ${ }^{6}$ LKS Faculty of Medicine, The University of Hong Kong, Hong Kong, China
\end{abstract}

\begin{abstract}
The number of people, and proportion of the world population, living in cities has increased steadily, with 4.2 billion urban residents now accounting for $55 \%$ of the world's population (fig 1). That urban living influences health is well recognised and increasingly included in broader discussions about cities and sustainable human development. The general tone of such discourse, however, tends towards the negative aspects of infectious outbreaks, vehicular pollution, waste disposal, and unhealthy lifestyles ${ }^{2}$ rather than the "positive and progressive aspects of cities ... recognised by historians, economists, and other social scientists."
\end{abstract}

Empirical evidence strongly points to urban residents having better health than their rural counterparts since at least the early to mid 20th century, in high income as well as low and middle income countries. ${ }^{3-6}$ The health advantages of urban living, however, are unevenly distributed in cities, with massive inequalities existing over short distances (fig 2). ${ }^{4-11}$ Our urbanising world provides an opportunity, and an imperative, to not only further improve population health in cities but also to leverage cities as nodes in a natiotrafinal and global network to improve health in and across countries. Reducing inequalities is fundamental because population health suffers where inequalities are larger. ${ }^{12}$

The urban health literature commonly uses the "healthy city" concept to frame discussions. ${ }^{14} 15$ The idealised healthy city, although aspirational, can easily be disconnected from the complex dynamics of urban development, in which cities' demographics and social, natural, built, and food environments are constantly changing through interactions between individual, corporate, and public actions. Limited attention has also been given to the essential role of urban services, including healthcare, childcare, and public safety. Thus the policy challenge for improving health in cities, first laid out a century ago by Chapin, ${ }^{16}$ remains - to identify and implement institutional and technical innovations in every sector that form transition pathways to better health, taking into account the contemporary local social, demographic, and economic conditions. We discuss a set of themes in which municipal governments and administrators (referred to as "cities" hereafter) can foster innovation in technology and practice and achieve economies of scale in services that improve the health of their own residents and benefit a wider geography, with emphasis on their role in reducing health inequalities.

\section{Defining the role of cities in global health}

\section{Environment}

The infrastructures, technologies, and regulations that collectively provide clean sanitation and water have been a cornerstone of health improvement in cities for centuries. ${ }^{16-18}$ Although much recent attention has been on water quality, many cities face the additional challenge of severe water shortages due to inefficient management and unfavourable natural or human induced hydrological cycles. Shortages have led to water rationing and rising water costs, which disproportionately affect poor people. Water resource management (especially allocation among agricultural, industrial, and human use) often goes beyond the jurisdiction of individual cities, but cities can incentivise and encourage the use of technologies for more efficient and robust use of water resources. These include storm 
water collection and drainage, distributed or on-site treatment of wastewater, and source separation of human waste. ${ }^{19}$

Other urban environmental factors that affect health include air and noise pollution, green space, and the overwhelming volume of general solid waste, as well as electronic, battery, industrial, and other toxic waste. Cities can reduce pollution through infrastructure planning and regulations that change energy or transport technologies and behaviours. But the inequality challenge remains, as poorer areas are often designated to accommodate waste from richer areas of the same city or even from other locations, some in different continents. ${ }^{20}$

\section{Housing}

Housing affects health through both social (interaction versus isolation) and physical (temperature, moisture, mould, pollutants, sunlight, and crowding) environments. ${ }^{21}$ The agglomeration benefits that attract people to cities inevitably create higher living densities and housing costs, which in larger cities are exacerbated by the presence of highly paid expatriate staff employed by multinational corporations. The high cost of housing in cities leads to inequalities in housing quality and neighbourhood conditions (fig 3). ${ }^{22}$ It also reduces the income that people have available for food, healthcare, energy, education, and leisure or limits the time that people can spend on these because they commute longer distances. In rapidly growing cities, slums have emerged as homes for millions of urban poor people who are priced out of the formal housing market and live in crowded, windowless, and flimsy structures without adequate sanitation and other essential services. ${ }^{23} 24$

Cities have traditionally cleared slums and redeveloped these neighbourhoods. Unless accompanied by housing policies that support poor people, however, such actions can push poor families to farther locations and can affect their job opportunities and access to services such as education and healthcare. ${ }^{25}$ Slum upgrading, through equitable land tenure, construction of sanitation, water, electricity, and road infrastructure, and provision of essential services, has the potential to improve the health of slum residents without displacing them, but must overcome the political influence of powerful elites who benefit from rents on slum dwellings and from the sale of land for private development. ${ }^{25-28}$ More broadly, city governments can tackle housing challenges through high quality state owned social housing and through fiscal policies and regulation that incentivise housing associations, public-private partnerships, or private entities to develop safe and healthy housing that operates at low cost and in the interest of low income people. ${ }^{29-31}$

\section{Nutrition}

Although urban living is often taken as a proxy for unhealthy eating, cities provide opportunities for better nutrition. ${ }^{5}$ Infrastructures such as roads and electricity facilitate the trade, transport, and storage of food, which can reduce the effect of agricultural shocks and seasonality and enhance dietary diversity. At the same time, the commercial nature of food provision in cities can raise the cost of healthy foods and enable transnational and local food industries to market unhealthy foods. This is especially true in poor and marginalised communities (fig 4), where a combination of cost and limited time and space for cooking healthy meals leads to poor nutrition. Cities can leverage the benefits of food trade and sales through food hygiene laws and inspections and through healthy food programmes that support poor people, such as healthy school meals, food stamps designated for healthy foods, ${ }^{33}$ requiring the availability of healthy foods such as fruits in grocery stores, and restricting the marketing and sales of unhealthy foods. Cities can also use their planning and zoning powers to facilitate access to land and water for urban agriculture, which can improve food security and nutrition. ${ }^{34}$

\section{Addiction}

Cities provide a focal point for the distribution and consumption of addictive substances (tobacco, alcohol, and illicit drugs). ${ }^{35}$ Both commercial and informal suppliers typically target poor and vulnerable communities. ${ }^{36}$ Cities have an important role in tackling addiction and its health consequences ${ }^{37}$; they can, for example, levy additional taxes beyond national or provincial dues; restrict the locations and opening times of alcohol and tobacco outlets through licensing; regulate product advertising; legislate smoke-free areas; raise the minimum legal age for sales; institute sobriety checkpoints and random breath testing; implement designated driver campaigns; sanction the use of currently illicit substances in monitored locations for harm reduction; and provide addiction counselling and treatment services. ${ }^{38}$

\section{Universal health coverage}

Universal health coverage has emerged as a priority for national and international health agencies. Although financial protection and limiting out-of-pocket payments often comes under national or provincial jurisdiction, some cities provide additional safety nets for those without insurance coverage. ${ }^{39}$ More importantly, health services in cities both provide care to their own residents and act as referral hubs for rural residents who need specialist care because the higher population density and reduced distances in cities facilitate regular and frequent interaction with primary health services, and provide economies of scale for secondary and tertiary care. ${ }^{39}$ Achieving universal coverage and enhancing health equity requires careful planning of service location and operating times to serve low income families with long and inflexible work hours and to reverse the current pattern of more affluent groups getting the benefits of high quality urban health services. ${ }^{40-43}$ Finally, city living might isolate vulnerable groups, including elderly people, with no local social networks and limit or delay their use of health services. Compensating mechanisms include an integrated local primary health and social care system and combining new sensing and communication technologies with key health workers to ensure interactions are made in good time to prevent severe declines in health.

\section{Public safety and emergency response}

Public safety and emergency response are essential functions of cities that, under normal conditions, can contribute to health through prevention (enhanced neighbourhood and traffic safety and reduction in crime) and through mitigating adverse outcomes from acute events (faster response to heart attacks, road traffic crashes, and fires). Achieving these objectives requires sustained investment in infrastructure and personnel, including street lighting, fire services, ambulances, police, and paramedics, as well as training and oversight to ensure equal treatment of citizens. Extreme events can overwhelm local services and thus require an agreed contingency plan that includes a well rehearsed command structure, a communications strategy, recovery management, and a good understanding of the role of governmental agencies and civil society, which should all be established before the crisis arises. 


\section{Infectious disease outbreaks}

Because of their population concentration and connectivity, cities are a rate enhancing or rate limiting gateway to infectious disease transmission, with consequences that extend beyond health, as seen recently with Ebola. This makes detection and control of epidemics a direct function of cities, which requires robust city based outbreak surveillance, detection, and control systems that are coordinated between neighbouring municipalities. Non-drug interventions are often the first-and sometimes the only (especially in resource poor settings)—-line of defence against outbreaks. Quarantine, isolation, and contact tracing are almost always carried out by municipal public health authorities. Cities also have a major role in the distribution of antiviral drugs, for prophylaxis and for treatment, and vaccination campaigns, both of which featured prominently in the $2009 \mathrm{H} 1 \mathrm{~N} 1$ pandemic. ${ }^{44}$ Finally, an important route for introduction of infections in cities is when infectious agents cross the species barrier in wholesale and retail markets, initiating a cascade of events that ultimately seed an epidemic. ${ }^{45}$ Limiting such events requires a "one health" approach that recognises the critical interface between animal and human health and extends to agriculture, aquaculture, and animal husbandry practices.

\section{Smart cities and emerging economies and technologies}

Advances in sensing, computing, and communication technologies are creating unprecedented opportunities, as well as challenges, to improving urban health and reducing inequalities. Examples include the use of digital footprints for tracking disease and mobile phones for health information and alerts; distributed sensor technologies to detect water and air pollution, mould, traffic flows and crashes, and crime; better monitoring of, and response to, health of newborns and elderly people through personalised sensing; better nutrition through online shopping and home delivery; and more active or more efficient transportation through bicycle and car sharing systems and eventually autonomous vehicles. Such technologies also have the potential to worsen health and widen inequalities. Sharing systems like Airbnb may be affecting the already limited housing supply in cities, and the gig economy may be worsening social inequalities by reducing wages and job security. ${ }^{43}{ }^{46}$ Home delivery of goods and services and diversion of traffic to reduce congestion could increase air pollution and the risk of traffic related injuries in residential areas, and reliance on online shopping may increase social isolation. Individual cities cannot stop such trends but will need to carefully monitor their penetration and impact and be prepared to intervene through agile legislative, regulatory, and fiscal policies to maximise benefits and minimise harms, especially in terms of inequalities.

\section{Migrant, transient, and peri-urban populations}

Cities around the world are homes to tens of millions of refugees, asylum seekers, undocumented migrants, and internally displaced persons. City boundaries and residents are also increasingly blurred by large groups of transient populations who seek jobs in cities, even in tightly controlled systems such as the Chinese "hukou" (household registration) system, and by large peri-urban communities. These groups and areas are functionally part of the city but are often administratively hidden and not entitled to full land and residency rights or to services such as waste collection, home water connections, social insurance, and healthcare, which worsens social and health inequalities in cities. ${ }^{47}$ Agricultural based industries and off-farm activities that generate sustainable income and better rural infrastructure and services can slow the rural-urban migration. ${ }^{48}$ But overcoming these inequalities in cities can be achieved only by city administrations acknowledging the presence, contributions, and needs of migrant, transient, and peri-urban populations and by providing equitable access to quality healthcare and promotion of rights to safe accommodation and working environment.

\section{Conclusions}

The concentration of knowledge and innovation, economic activity, healthcare, education, and other public services endows cities with the potential to deliver substantial improvements to the health and wellbeing of their residents and those of other parts of the country. ${ }^{1637}$ Further, the local politics in cities, whereby politicians and citizens live side by side as members of the same community, provide an opportunity to avoid and resist the exclusionary and austerity trends seen in national politics and economics around the world and to make health inequalities the central focus of urban health policies. A challenge to this, described a century ago by Chapin and equally relevant today, ${ }^{16}$ is the fragmented administrative and technocratic systems in cities. When coupled with pressure from various interest groups, these can easily lead to either continuing cities' own past choices or replicating those elsewhere. To overcome this inertia and harness the health enhancing potential of cities requires using the cross sectoral roles of mayors and city councils to build health and health equity in all policies. Beyond individual cities, global and regional city networks (such as United Cities and Local Governments https://www. uclg.org/ and the C40 network https://www.c40.org/) provide an opportunity for shared learning and coordinated experimentation of innovative policies and how these can be adapted to contemporary local social, demographic, and economic conditions. Building on this thinking, The BMJ is launching a series of articles on important themes in urban health, such as emerging economies and technologies; extreme events and emergencies; housing; migration; and water resource management. The series will focus on actions that cities can take to reduce health inequalities and deliver on their potential to create better and healthier lives for all.

Competing interests: We have read and understood BMJ policy on declaration of interests and declare the following interests: None. This work is supported by the Wellcome Trust (grants 205208/Z/16/Z and 209376/Z/17/Z).

Contributions: $M E$ and GML developed the manuscript concept and wrote the initial draft. All other authors contributed to contents and writing. ME is the guarantor.

Provenance and peer review: Commissioned; externally peer reviewed.

1. United Nations Department of Economic and Social Affairs (Population Division). World Urbanization Prospects: The 2014 Revision. Population Division of the Department of Economic and Social Affairs of the United Nations Secretariat, 2015.

2 World Health Organization. Global report on urban health: equitable healthier cities for sustainable development. World Health Organization, 2016.

3 Leon DA. Cities, urbanization and health. Int J Epidemiol 2008;37:4-8. 10.1093/ije/dym271 18187525

4 Dye C. Health and urban living. Science 2008;319:766-9. 10.1126/science.1150198 18258905

5 Krumdiek CL. The rural-to-urban malnutrition gradient. A key factor in the pathogenesis of urban slums. JAMA 1971;215:1652-4. 10.1001/jama.1971.031802300620125107687

6 Keyfitz N. United States and world populations. In: Resources and man-a study and recommendations. WH Freeman \& Co Publishers, 1969: 43-64.

7 Bennett JE, Li G, Foreman K, etal . The future of life expectancy and life expectancy inequalities in England and Wales: Bayesian spatiotemporal forecasting. Lancet 2015;386:163-70 . 10.1016/S0140-6736(15)60296-3 25935825

8 Zhou Z, Dionisio KL, Arku RE, etal . Household and community poverty, biomass use, and air pollution in Accra, Ghana. Proc Natl Acad Sci U S A 2011;108:11028-33. 10.1073/pnas.1019183108 21690396

9 Urban Age Programme. Cities and Social Equity. London School of Economics and Political Science, 2009. 
10 Ravallion M, Chen S, Sangraula P. New evidence on the urbanization of global poverty Popul Dev Rev 2007:33:667-701. 10.1111/j.1728-4457.2007.00193.x.

11 Borrell C, Pons-Vigués M, Morrison J, Díez E. Factors and processes influencing health inequalities in urban areas. J Epidemiol Community Health 2013;67:389-91. 10.1136/jech-2012-202014 23413097

12 World Health Organization. UN Habitat. Global report on urban health: equitable, healthier cities for sustainable development. World Health Organization, 2016.

13 Habitat III Secretariat. New Urban Agenda. United Nations, 2017.

14 Rydin Y, Bleahu A, Davies M, etal . Shaping cities for health: complexity and the planning of urban environments in the 21st century. Lancet 2012;379:2079-108. 10.1016/S0140-6736(12)60435-8 22651973

15 Sallis JF, Bull F, Burdett R, etal . Use of science to guide city planning policy and practice: how to achieve healthy and sustainable future cities. Lancet 2016;388:2936-47. 10.1016/S0140-6736(16)30068-X 27671670

16 Chapin CV. The relative values of public health procedures. JAMA 1917;LXIX:90-5 10.1001/jama.1917.02590290012004.

17 Preston SH, Van de Walle E. Urban French mortality in the nineteenth century. Popul Stud (Camb) 1978;32:275-97. 10.1080/00324728.1978.10410715 11630579

18 Moraes LRS, Cancio JA, Cairncross S, Huttly S. Impact of drainage and sewerage on diarrhoea in poor urban areas in Salvador, Brazil. Trans $R$ Soc Trop Med Hyg 2003:97:153-8. 10.1016/S0035-9203(03)90104-0 14584367

19 Larsen TA, Hoffmann S, Lüthi C, Truffer B, Maurer M. Emerging solutions to the water challenges of an urbanizing world. Science 2016;352:928-33. 10.1126/science.aad8641 27199414

20 Sexton K, Adgate JL. Looking at environmental justice from an environmental health perspective. J Expo Anal Environ Epidemiol 1999;9:3-8. 10.1038/si.jea.7500021 10189622

21 Goldstein G, Novick R, Schaefer M. Housing, health and well-being: an international perspective. J Sociol Soc Welf 1990;17:161-81.

22 Braubach M, Fairburn J. Social inequities in environmental risks associated with housing and residential location--a review of evidence. Eur J Public Health 2010;20:36-42. 10.1093/eurpub/ckp221 20047933

23 Rashid SF. Strategies to reduce exclusion among populations living in urban slum settlements in Bangladesh. $J$ Health Popul Nutr 2009;27:574-86. 10.3329/jhpn.v27i4.3403 19761090

24 Ezeh A, Oyebode O, Satterthwaite D, etal . The history, geography, and sociology of slums and the health problems of people who live in slums. Lancet 2017;389:547-58. 10.1016/S0140-6736(16)31650-6 27760703

25 Lilford RJ, Oyebode O, Satterthwaite D, etal . Improving the health and welfare of people who live in slums. Lancet 2017:389:559-70. 10.1016/S0140-6736(16)31848-7 27760702

26 Turley R, Saith R, Bhan N, Rehfuess E, Carter B. Slum upgrading strategies involving physical environment and infrastructure interventions and their effects on health and socio-economic outcomes. Cochrane Database Syst Rev 2013;1:CD010067. 10.1002/14651858.CD010067.pub2. 23440845

27 World Bank. Cities alliance for cities without slum: action plan for moving slum upgrading to scale. World Bank, 2013

28 Henderson JV, Venables AJ, Regan T, Samsonov I. Building functional cities. Science 2016;352:946-7. 10.1126/science.aaf7150 27199420

29 Berdik C. The fixer-uppers. Harvard Public Health Magazine 2016 https://www.hsph harvard.edu/magazine/magazine_article/the-fixer-uppers/

30 van der Veer J, Schuiling D. More than just housing. In: Mamadouh V, Wageningen A, eds. Urban Europe: Fifty Tales of the City. Amsterdam University Press, 2016: 275-82.

31 King R, Orloff M, Virsilas T, et al. Confronting the urban housing crisis in the global south: adequate, secure, and affordable housing. 2017. https://www.wri.org/sites/default/files/ towards-more-equal-city-confronting-urban-housing-crisis-global-south.pd
32 Public Health England. Fast food outlets: density by local authority in England. https:// www.gov.uk/government/publications/fast-food-outlets-density-by-local-authority-in-england

33 Bleich SN, Rimm EB, Brownell KDUS. US Nutrition Assistance, 2018 - modifying SNAP to promote population health. N Engl J Med 2017;376:1205-7. 10.1056/NEJMp1613222 28355501

34 Brown KH, Jameton AL. Public health implications or urban agriculture. J Public Health Policy 2000;21:20-39. 10.2307/3343472 10754796

35 Sureda X, Villalbí JR, Espelt A, Franco M. Living under the influence: normalisation of alcohol consumption in our cities. Gac Sanit 2017;31:66-8.

10.1016/.gaceta.2016.07.018 27769724

36 Fone D, Dunstan F, White J, etal . Change in alcohol outlet density and alcohol-related harm to population health (CHALICE). BMC Public Health 2012;12:428. 10.1186/1471-2458-12-428 22691534

37 Diller PA. Why do cities innovate in public health? Implications of scale and structure. Washington University Law Review 2014;91(5). https://openscholarship.wustl.edu/law lawreview/vol91/iss5/7l

38 Mooney JD, Holmes J, Gavens L, etal . Investigating local policy drivers for alcohol harm prevention: a comparative case study of two local authorities in England. BMC Public Health 2017;17:825. 10.1186/s12889-017-4841-3 29047389

39 Gusmano MR, Rodwin VG, Weisz D. Health Care in World Cities. Johns Hopkins University Press, 2010.

40 Morris S, Sutton M, Gravelle $\mathrm{H}$. Inequity and inequality in the use of health care in England: an empirical investigation. Soc Sci Med 2005;60:1251-66. 10.1016/j.socscimed.2004.07.016 15626522

41 Goddard M, Smith P. Equity of access to health care services: theory and evidence from the UK. Soc Sci Med 2001;53:1149-62. 10.1016/S0277-9536(00)00415-9 11556606

42 Ahmed SM, Evans TG, Standing H, Mahmud S. Harnessing pluralism for better health in Bangladesh. Lancet 2013;382:1746-55. 10.1016/S0140-6736(13)62147-9 24268003

43 Booth R. DPD courier who was fined for day off to see doctor dies from diabetes. The Guardian 2018. https://www.theguardian.com/business/2018/feb/05/courier-who-wasfined-for-day-off-to-see-doctor-dies-from-diabetes

44 Leung GM, Nicoll A. Reflections on pandemic (H1N1) 2009 and the international response. PLoS Med 2010;7:e1000346. 10.1371/journal.pmed.1000346 20957189

45 Peiris JS, Cowling BJ, Wu JT, etal . Interventions to reduce zoonotic and pandemic risks from avian influenza in Asia. Lancet Infect Dis 2016;16:252-8. 10.1016/S1473-3099(15)00502-2 26654122

46 Elliott L. Fourth Industrial Revolution brings promise and peril for humanity. The Guardian 2016. https://www.theguardian.com/business/economics-blog/2016/jan/24/4th-industrialrevolution-brings-promise-and-peril-for-humanity-technology-davos

47 Feler L, Henderson JV. Exclusionary policies in urban development: Under-servicing migrant households in Brazilian cities. J Urban Econ 2011;69:253-72. 10.1016/j.jue.2010.09.006 22707807

48 Epstein TS, Mumtaz S, Chaudhary MA. Redressing the rural-urban imbalance. Pak Dev Rev 2003;42:445-66.10.30541/v42i4lpp.445-466 .

Published by the BMJ Publishing Group Limited. For permission to use (where not already granted under a licence) please go to http://group.bmj.com/group/rights-licensing/ permissionsThis is an Open Access article distributed in accordance with the terms of the Creative Commons Attribution (CC BY 4.0) license, which permits others to distribute, remix, adapt and build upon this work, for commercial use, provided the original work is properly cited. See: http://creativecommons.org/licenses/by/4.0/. 


\section{Figures}

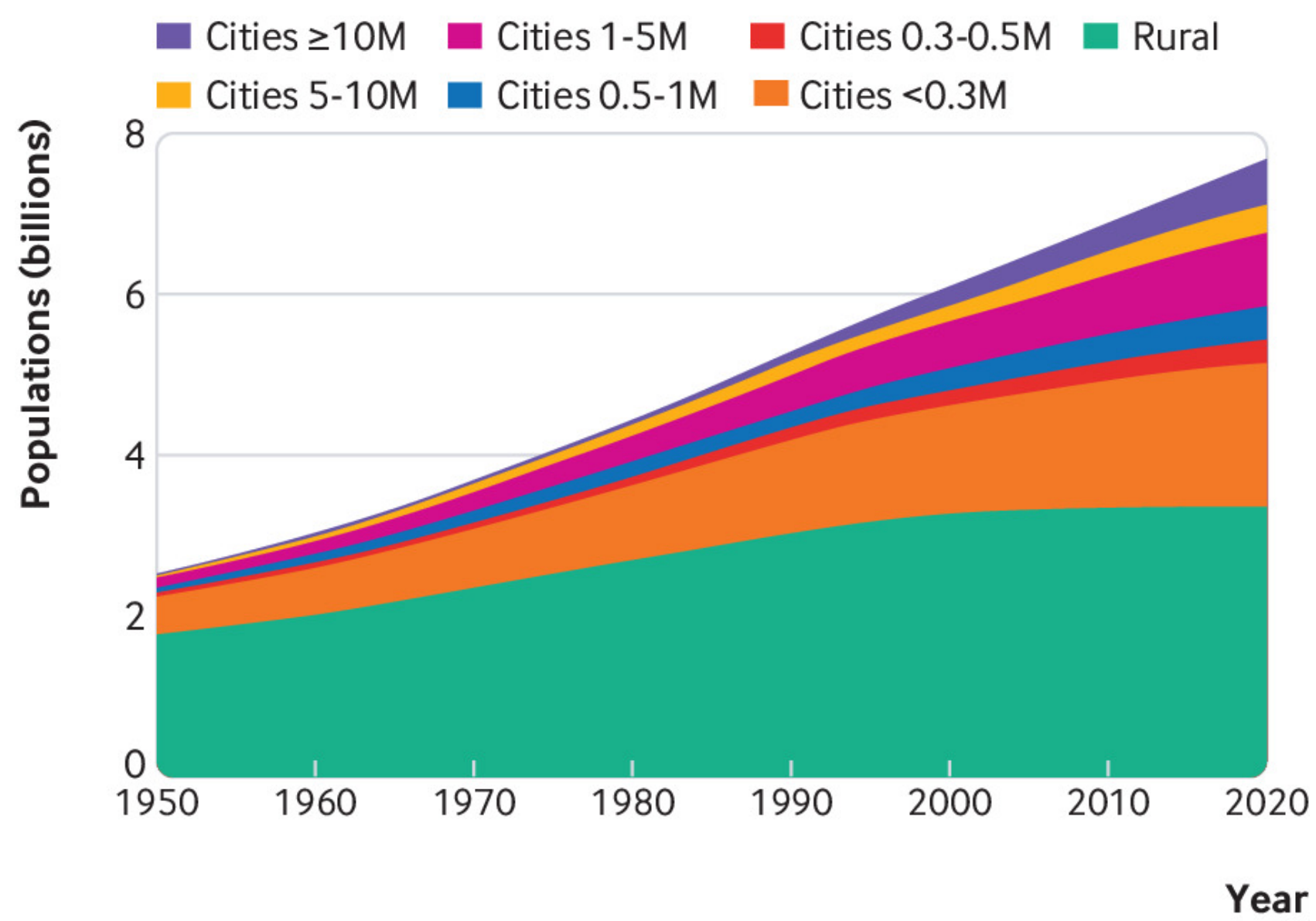

Fig 1 Number of people living in rural areas and in cities in the world. Data are from the World Urbanization Prospects ${ }^{1}$ 

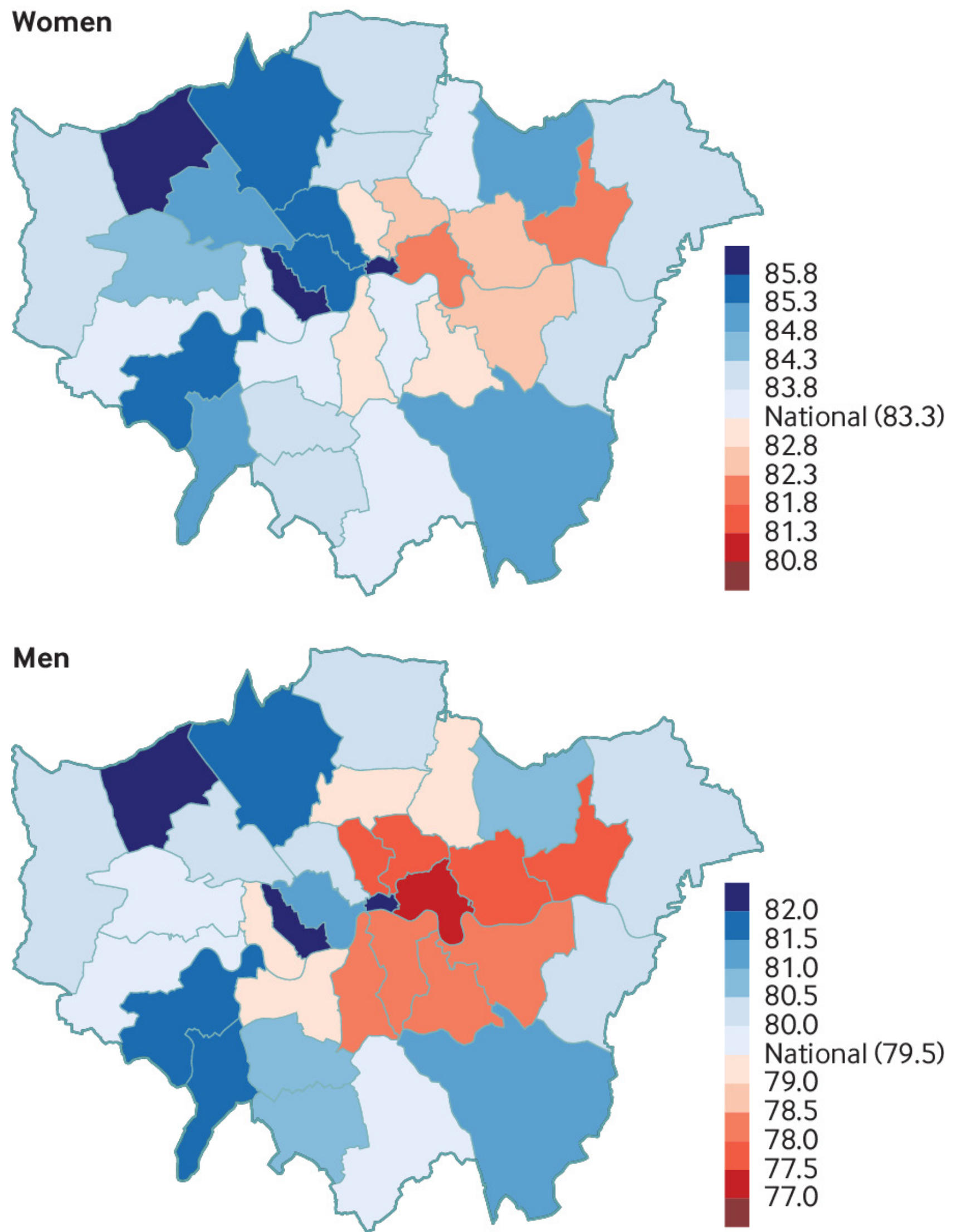

Fig 2 Life expectancy at birth in 2012 in London's local authorities. Data are from Bennett et al ${ }^{7}$ 

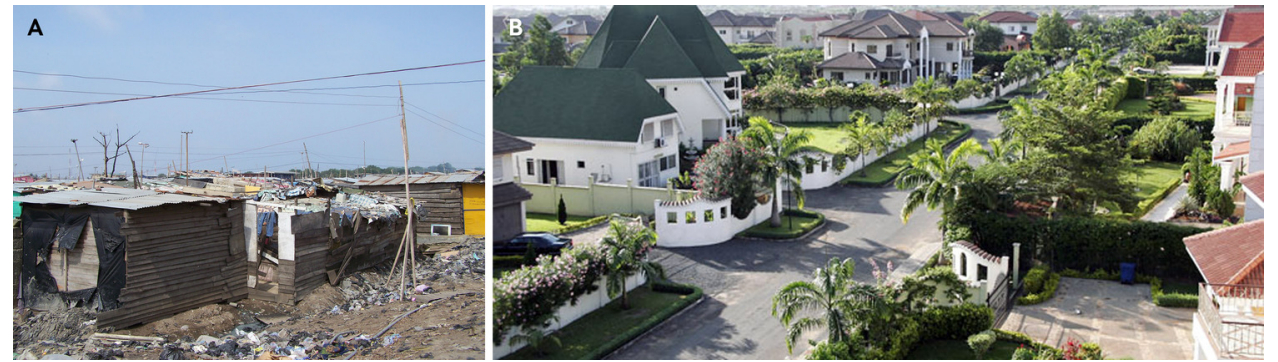

Fig 3 Homes in poor (A) and wealthy (B) neighbourhoods of Accra, Ghana, showing the extent of inequality in housing and the living environment just kilometres apart

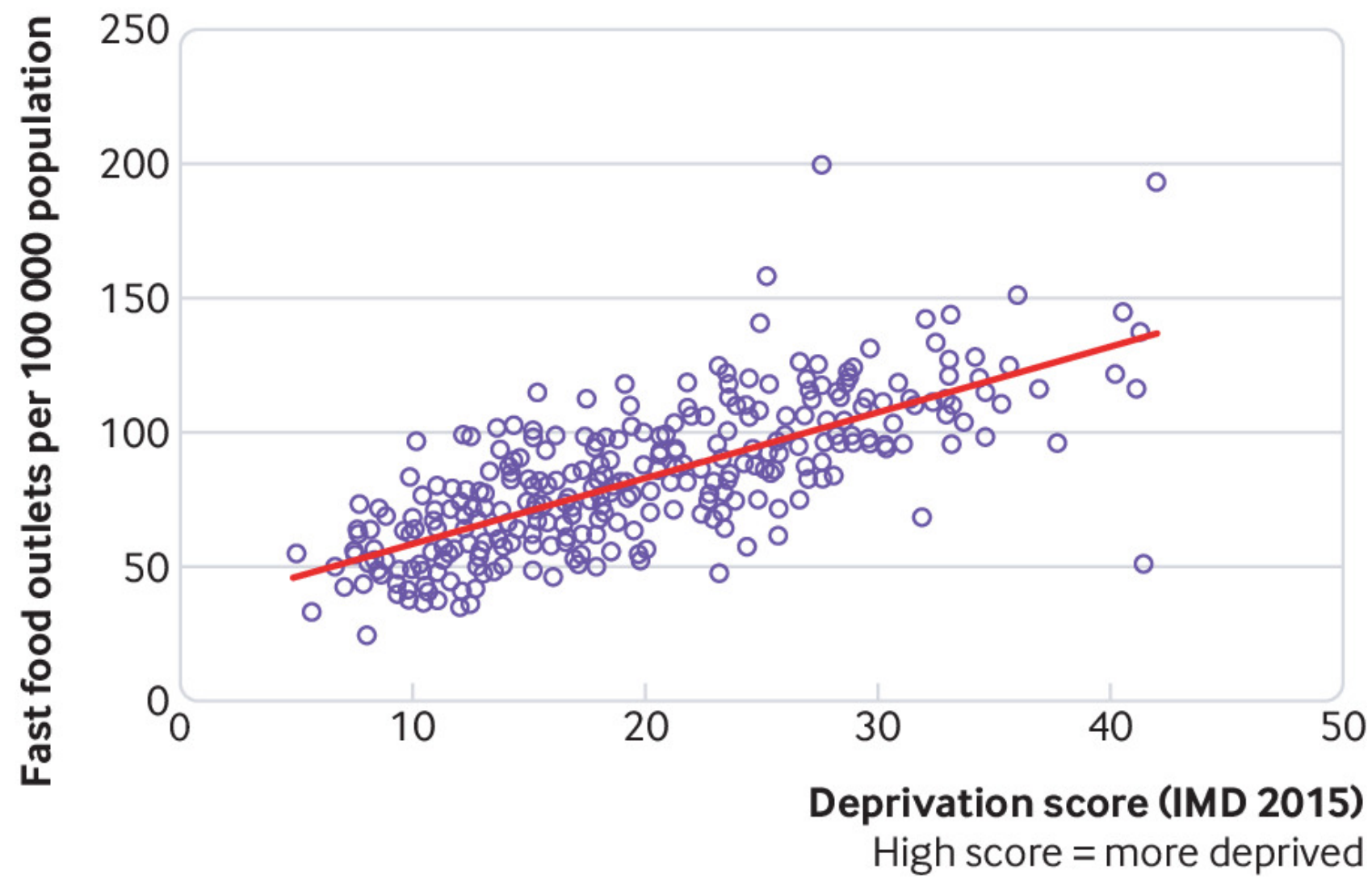

Fig 4 The association between deprivation and density of fast food outlets across England's local authorities (source: Public Health England $)^{32}$ 